\title{
Horgan and Tienson on phenomenology and intentionality
}

\author{
Andrew Bailey $\cdot$ Bradley Richards
}

(C) Springer Science+Business Media Dordrecht 2013

\begin{abstract}
Terence Horgan, George Graham and John Tienson argue that some intentional content is constitutively determined by phenomenology alone. We argue that this would require a certain kind of covariation of phenomenal states and intentional states that is not established by Horgan, Tienson and Graham's arguments. We make the case that there is inadequate reason to think phenomenology determines perceptual belief, and that there is reason to doubt that phenomenology determines any species of non-perceptual intentionality. We also raise worries about the capacity of phenomenology to map onto intentionality in a way that would be appropriate for any determiner of content/fixer of truth conditions.
\end{abstract}

Keywords Phenomenology · Intentionality · Phenomenal character ·

Consciousness $\cdot$ Perception

In a seminal paper Horgan and Tienson (2002) argue that some intentional content is constitutively determined by phenomenology alone. They support this claim with an argument designed to show that certain intentional states are fixed by phenomenal states. ${ }^{1}$ However, in this paper we argue that what Horgan and Tienson (hereafter HT) call phenomenal intentionality requires a certain kind of correlation of phenomenal states and phenomenal intentional states, which HT do not present

\footnotetext{
${ }^{1}$ We take Horgan and Tienson (2002) to be a canonical statement of the position; it is further amplified and defended in Horgan et al. (2005, 2006), Graham and Horgan (2000, 2008), and Graham et al. (2007, 2009).
}

Authors are listed alphabetically; authorship is fully symmetrical.

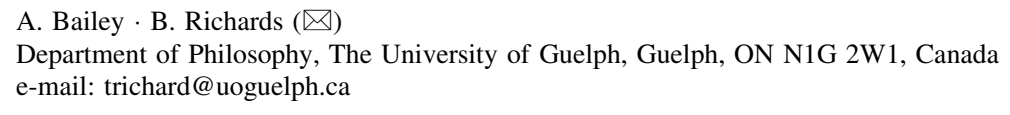


arguments for. Furthermore, we suggest, accepting the stronger equivalence claim necessary to make phenomenal intentionality plausible would entail combining the principle of phenomenal intentionality with some form of representationalist theory of consciousness, and so calling into question the putative priority of the phenomenal.

HT extend their principle of phenomenal intentionality beyond perceptual belief to conscious cognitive states more generally, such as beliefs (hopes, fears, etc.) about what is for dinner tonight. We argue that, whatever plausibility the thesis of phenomenal intentionality might have for perceptual belief, it fails for nonperceptual intentionality. Finally, we raise a more general concern about projects that attempt to bind phenomenality and intentionality tightly together: the type of compositionality evidenced by the phenomenal is sufficiently different from that familiar in the case of the intentional that it is hard to see how the two can plausibly covary.

\section{Horgan and Tienson's argument}

HT assert the following principle (2002, p. 520) ${ }^{2}$ :

Phenomenal Intentionality: There is a kind of intentionality, pervasive in human mental life, that is constitutively determined by phenomenology alone.

They "articulate and sharpen" this claim as follows (p. 524) ${ }^{3}$ : "There is a kind of intentional content, pervasive in human mental life, such that any two possible phenomenal duplicates have exactly similar intentional states vis-à-vis such content." They label this sub-species of content phenomenal intentional content. Two creatures are stipulated to be phenomenal duplicates just in case "each creature's total experience, throughout its existence, is phenomenally exactly similar to the other's" (p. 524).

HT argue for the thesis of phenomenal intentionality on the basis of what they take to be a representative example: you and your phenomenal duplicate having the experience of seeing a picture hanging crooked. The sensory-phenomenal experience you share, according to HT, "determines conditions of accuracy" for this experience, independently of any other factors.

In order for such an experience to be accurate, there must be a picture before oneself, and it must be crooked. That these phenomenally identical experiences all have the same truth conditions is reflected in the fact that each of the experiences is subject in the same way to investigation as to whether it is accurate. (p. 524)

\footnotetext{
${ }^{2}$ Similar recent attempts to argue for a tight connection between phenomenality and intentionality are Charles Siewert (1998) and Brian Loar (2002, 2003). John Searle (1992) and Galen Strawson (1994) are also prominent advocates of the view that phenomenology is a pre-requisite for 'genuine' intentionality; see also McGinn (1988) and Addis (1989).

${ }^{3}$ All page references are to Horgan and Tienson (2002) unless otherwise noted.
} 
One might, for example, have the experience of seeming to oneself to be using a level to measure the angle of the picture frame, or of seeming to be changing the lighting to see if an errant shadow is to blame. HT claim that tests such as these can show that an experience is inaccurate (e.g. if one has the experience as of passing one's hand right through the picture as if it is a holographic image), and also suggest that they can reveal an experience to be accurate. That is, they propose that phenomenal experience, all by itself, fixes a set of truth-conditions, and hence a species of content: phenomenal intentional content.

HT contrast this variety of content with the "different truth conditions" (p. 524) that are "determined in part by items in the experiencer's environment that satisfy the experiencer's phenomenology" (p. 525). HT label these wide truth conditions, as opposed to the narrow truth conditions that "are completely determined by phenomenology" (p. 528).

Furthermore, HT argue that not only perceptual experience but perceptual belief have this phenomenal intentional content.

Your phenomenal duplicate accepts the presentations delivered by perceptual experience-accepts, for example, that there is a picture and a wall-just as you do... These 'belief-wise' acceptance states ... are experienced as having the same belief-specific role: the same apparent input conditions, involving apparent deliverances of the apparent body's apparent senses, and the same apparent effects, involving experiences of apparently acting appropriately with regard to the apparent world as presented. It seems intuitively clear that a belief-wise acceptance state with these phenomenological features is a genuine belief. (p. 525)

Still further, it is not only perceptual beliefs that have phenomenal intentional content, argue HT, but also "a wide range of propositional-attitude states whose content goes well beyond the presentations of perceptual experience itself" (p. 525). For each phenomenal duplicate, the belief that "The picture behind me is crooked" will have exactly the same phenomenologically-determined narrow truth conditions, which, as above, can be characterised in terms of experiential "methods of accuracy assessment" (p. 525). HT's thesis of the phenomenology of intentionality (or PI) states that paradigmatic mental states (e.g., beliefs and desires), when conscious, have phenomenal character that is inseparable from their intentional content. Phenomenal intentionality adds that the phenomenal intentional content of those states is determined by their phenomenal character.

HT conclude,

[w]e take it that this thought-experimental argument supports the idea that each specific occurrent intentional state with phenomenal intentional content is constitutively determined by its own distinctive phenomenal character-viz., the what-it's-like of undergoing that particular attitude-type vis-à-vis that particular phenomenal intentional content. (p. 526)

Thus, they say, any experiencing creature that undergoes "the distinctive phenomenal what-it's-like of believing that a picture is hanging crooked" (p. 526) thereby believes that there is a picture hanging crooked. 
Suppose, for the sake of argument, that HT's central case study is convincing enough to make plausible the notion that some phenomenal experience is tightly linked to representational content, and that any two relevantly phenomenally identical states will share some aspect of that representational content. ${ }^{4}$ Nevertheless, serious problems remain and we will identify two here (and argue that they are suggestive of a more general concern):

(i) The notion of perceptual phenomenal content that HT's examples can establish is much too weak to capture the intuitions that we suspect it is intended to bolster, and which provide the notion of phenomenal intentional content with much of its prima facie plausibility. At most HT establish that a certain phenomenal state $\mathrm{P}$ fixes a certain intentional state $\mathrm{Q}$. However, to make plausible the conclusion that $\mathrm{P}$ constitutively determines $\mathrm{Q}$ requires a stronger relation of covariation. Otherwise, there is no reason why $\mathrm{P}$ states should constitute $\mathrm{Q}$ states; or at least the reason doesn't seem to be that $\mathrm{P}$ states are $P$, since that is not necessary for Q states. Yet if HT accept P-Q covariation they need an additional explanation to justify the priority of the phenomenal: why is it that "mental states have their content in virtue of their phenomenology" (p. 520), rather than vice versa?

(ii) The notion of propositional phenomenal content argued for by HT, on the other hand, is much too strong, and likewise violates the intuitions that we suspect it is intended to bolster. If the determining phenomenology is taken to be sensory the relationship cannot plausibly be strengthened to covariation. If it is taken to be non-sensory the relationship must be strengthened to covariation; however, this motivates the opposite determination relation-that is, it supports the claim that intentional states determine the associated phenomenal contents.

\section{Perceptual phenomenal content}

Assume that, as HT assert, fixing the phenomenal fixes an important category of perceptual content. They outline the intentionality of phenomenology (IP hereafter) as follows:

Mental states of the sort commonly cited as paradigmatically phenomenal (e.g., sensory-experiential states such as color-experiences, itches, and smells) have intentional content that is inseparable from their phenomenal character. (p. 520)

Thus, any creature undergoing phenomenal state $\mathrm{P}$ (e.g. one involving an experience of redness) must thereby necessarily be in intentional state Q (e.g. seeingaccurately or inaccurately-that something is red). HT urge, in accordance with phenomenal intentionality that states of type Q are "constitutively determined" by states of type $\mathrm{P}$, and make the case that $\mathrm{Q}$ is determined by $\mathrm{P}$ as a matter of

\footnotetext{
${ }^{4}$ This is a view similar to what David Chalmers (2004) calls a strong version of "weak representationalism."
} 
(metaphysical?) necessity rather than merely "nomically" (p. 520). Perhaps, then, we are supposed to take $\mathrm{P}$ and $\mathrm{Q}$ to be the same state. ${ }^{5}$ This has a certain pretheoretical appeal: red experiences are of red because they, as it were, look red-it is the redness of red experiences that makes them about red, rather than about, say, green or C\#. We do not say that HT mean to assert this view (or at least not as crudely as we put it here); but it does seem to us as if this intuition may account for some of the rhetorical appeal of their argument. ${ }^{6}$

But the identification or conflation of phenomenal with phenomenal intentional perceptual states does not follow from HT's argument. HT argue only that fixing the phenomenal fixes phenomenal intentional content; they do not provide any reasons to think that a given phenomenal intentional content must always be associated with a given phenomenal state (that is, that fixing the narrow content of a perception determines its phenomenology). Thus, even if "any two possible phenomenal duplicates have exactly similar [phenomenal] intentional states" (p. 524) it could still be the case that two experiencing creatures with very different phenomenality could have exactly similar phenomenal intentional perceptual content.

Consistently with HT's arguments, for example, my spectrum-inverted twin might have the same colour perceptions; the blind subjects of Paul Bach-y-Rita's famous experiment in which he gave them a kind of vision by hooking up a camera to an apparatus that provided tactile stimulation to their backs (Bach-y-Rita 1972), might have the same visual perceptual content as a sighted person; and so on. Indeed, it is compatible with HT's thesis of phenomenal intentionality that my zombie twin might have the same phenomenal intentional content as me: my P-states fix my Q-states, such that any creature with exactly similar P-states must have exactly similar Q-states; but my zombie twin does not have the same P-states as me, and so all bets are simply off with respect to his Q-states.

It seems clear that this is not something to which HT intend to be committed. What this shows is that they have not yet achieved the hard part of the argumentative burden they want to take on. What is needed is some argument to connect the intrinsic nature of phenomenal states with their intentional content. What we require is some reason to think that red experiences are 'of' red because they are like this rather than like that (like other colour experiences, for example, or experiences from other sensory modalities). This would close the circle and show that the phenomenal content of perception does indeed arise from the particular phenomenal nature of those experiences-and thus that sufficiently different experience would constitute different perceptual content. But HT do not make this case, and provide no guidance as to where such reasons might be sought.

\footnotetext{
${ }^{5}$ Kenneth Williford (2005) calls this the Thesis of Strong Inseparability: the view that "intentionality and phenomenality are but two sides of the same coin".

${ }^{6}$ Thus, David Chalmers (2004) focuses on the equivalence of phenomenal and representational properties in his discussion of the representational character of experience. He argues that a certain kind of equivalence fails, as do we, and that this blocks the prospects for some variants of what he calls 'representationalism' (he uses the term in a wider sense than is usual). However, the equivalence he is interested in - that between phenomenal properties and what he calls "pure representational properties" - is different from our concern here, and his arguments are not the same as ours. Indeed, Chalmers ultimately argues that phenomenal properties are identical with a kind of representational property, and so his views are in tension with those we defend below.
} 
There is a deeper problem here, that affects not only HT but anyone who seeks to put forward a thesis of constitutive phenomenal intentionality. ${ }^{7}$ It is not enough, we have suggested, for the phenomenal to fix the phenomenal intentional; it must do so because of the nature of its phenomenality. That is, all and only phenomenal states of a certain class (e.g. red sensations) will fix a given phenomenal intentional content (e.g. perceiving redness). But this requires a converse relationship to that which HT emphasize: there should be no phenomenal intentional content of type Q without phenomenality of type $\mathrm{P}$; that is, any phenomenal change will correspond to a change in intentionality. Yet this is precisely the thesis of representationalism (sometimes called intentionalism): there is no phenomenal difference without an intentional difference. ${ }^{8}$

HT, however, intend to distinguish themselves from representationalists: "typically they [representationalists] do not embrace PI [the phenomenology of intentionality]. Nor do they embrace phenomenal intentionality, since they hold that intentionality is prior to phenomenology" (p. 520). But if the phenomenal and the phenomenal intentional vary together then what sense can we make of the claim that one is prior to the other? In particular, what could support HT's assertion that the phenomenal grounds and "constitutes" the phenomenal intentional rather than, as the representationalist might hold, the other way around? HT-or any other proponent of the hypothesis of constitutive phenomenal intentionality-need an additional, independent argument for the priority of the phenomenal here, and it is not obvious from where it might come.

\section{Propositional phenomenal content}

When it comes to perceptual content, then, HT's thesis turns out to be too weak; but we shall now argue that for (non-perceptual) propositional attitudes it is too strong. HT defend the thesis (PI or the phenomenology of intentionality) that: "[m]ental states of the sort commonly cited as paradigmatically intentional (e.g. cognitive states such as beliefs, and conative states such as desires), when conscious, have phenomenal character that is inseparable from their intentional content" (p. 520). They write of the phenomenology of thinking that rabbits have tails, and the different phenomenology of wondering whether they do (p. 522); of wondering whether to cook meatloaf for dinner, thinking there's beer in the fridge, and hoping one's spouse isn't angry (p. 525).

Suppose this is right; then fixing this phenomenal character will, according to HT, fix the narrow-the phenomenal-intentional content of these propositional attitudes. However, in order to understand exactly what this claim amounts to it is

\footnotetext{
7 For example, Chalmers (2004), Kriegel (2009), Loar (2003), Pitt (2004), and Siewert (2003).

8 Leading representationalists, of somewhat varying stripes, include Peter Carruthers, Fred Dretske, William Lycan, and Michael Tye. We take the core commitment of representationalism, in this sense, to be the claim that phenomenal consciousness is grounded in, and metaphysically reducible to, intentionality. It is worth noting however, that "representationalism" is frequently used, following Chalmers (2004), to include all equivalence theses, even those that ground the intentional in the phenomenal, like Horgan and Tienson.
} 
necessary to distinguish between two conceptions of the associated phenomenology: the sensory and the non-sensory.

\subsection{Sensory phenomenology and propositional content}

Sensory phenomenology suggests mental images (and experiences in other sensory modalities). In the case of perceptual intentional content, which motivates the whole view, the idea of accuracy conditions and a unique variety of phenomenal intentional content is motivated by appeal to visual perceptual experience and so a kind of image. In Graham et al. (2007) it is clear that they prefer a non-sensory view. Nevertheless, given the examples used to explain and motivate the view it is important to consider the sensory view also.

On the sensory view, fixing the sensory phenomenology fixes the phenomenal intentional content. As we have already noted, this claim is distinct from one that holds that fixing narrow content thereby fixes phenomenology. But in the case of propositional intentional content, as opposed to perceptual content, attempting to establish this second determination relation holds little attraction, for it would commit us to the highly implausible thesis that everyone who believes $\mathrm{P}$ has exactly similar sensory phenomenology (and ditto for desiring, wondering about, fearing, etc. P). When I think about Hilary Clinton, or my grandmother, or rabbits, it seems clear that I may have quite different conscious states than you do, even if we restrict the phenomenological state in question to just those aspects of my consciousness that are relevant to my occurrent propositional attitude. When I ponder rabbits, the fleeting sensory images I experience, the inner verbalizations, the emotional associations, all may differ from yours. ${ }^{9}$

Even the weaker one-way dependency is dubious in the case of non-perceptual belief, moreover. The thesis of the phenomenology of intentionality is plausible in a way that out-runs the plausibility of phenomenal intentionality for the propositional attitudes. That there is something it is like to be conscious of a belief or desire, as well as of a sensation or emotion, is one thing. But that this phenomenality constitutes the narrow content of the propositional attitude is quite another.

Consider an example: suppose I consciously believe dinner will be meatloaf. It is not clear what a canonical phenomenal description of such a belief-state might be. Perhaps I have a fleeting visual image of a plate of meatloaf, or sub-vocalise "It's meatloaf night!" On the other hand, perhaps I have imagistic impressions of, say, my grandmother (famed for her meatloaf), or some chain of restaurants, or even the homonymous rock singer and his operatic vocalizings. Conversely, it is far from clear that any given set of occurrent phenomenal experiences determine a unique intentional content: there is no obvious reason why two creatures, with similar phenomenal histories, could not both experience exactly similar images of plates of meatloaf (or imagine a snatch of Bat Out of Hell) and yet have quite different beliefs - while I think it is meatloaf tonight, my twin might be thinking that soy-loaf is a healthy alternative snack.

\footnotetext{
${ }^{9}$ Robert A. Wilson makes a point rather like this in his (2003, pp. 416-417), though his other criticisms of HT's paper differ from those we make here.
} 
HT provide some further defence of their phenomenal intentionality thesis for propositional attitudes; but they do so by going beyond the occurrent phenomenology of conscious belief (or desire, etc.). That is, it is not what it feels like to believe $P$ that makes it a belief with the narrow content that P. Rather, HT's claim comes down to the observation that the truth conditions for empirical beliefs- the ways they may turn out to be accurate or inaccurate-can in the end be cashed out in terms of possible perceptual experiences (p. 525). Thus, two creatures that are phenomenal duplicates over their entire life-spans will have exactly the same reasons to endorse or deny any given belief.

Yet even fixing an entire lifetime of phenomenology might not be enough to fix content; in cases - surely very common-when we do not actually test our beliefs in experience (I thought it was going to be meatloaf, but work at the office kept me away from dinner that night and I never thought to check if I was right) then the phenomenology neither confirms nor refutes the belief. Appeal to possible but nonactual phenomenology to fix the content of beliefs surely will not save the thesis of phenomenal intentionality.

The crucial move HT try to make is to assert that "[t]he possibility of such tests is in some sense understood, if not explicitly phenomenologically given, in having the conscious belief" (p. 525). But this comes close to giving away the farm: it is not the phenomenology of belief that determines its content, it is the proposition's truthconditions (unless we concede that these truth conditions are 'in some sense' or 'implicitly' included in the phenomenological experience, but that is exactly what needs to be established). That we can understand these truth conditions as being, not the ways the world might be, but the ways our phenomenal world might present itself, does nothing to show that fixing the phenomenology of conscious belief fixes its content. Further, it is important to note that much of the superficial plausibility of this strategy rests on the intuitive idea of visual sensory phenomenology playing the determining role. We have seen that this view is implausible and that HT and GHT endorse the non-sensory view (discussed in our Sect. 3.2). Without sensory phenomenology the idea of tests that are understood or phenomenologically given and provide truth-conditions is opaque.

Even if the phenomenology associated with a belief does give truth conditions implicitly, as may be the case for the intentionality of phenomenology (we assert that this requires the equivalence found wanting in the discussion of the intentionality of phenomenology), the truth conditions are only those applying to perceptions and by extension perceptual beliefs (what HT describe as the beliefs formed by committing to the veracity of experiences in the context of other phenomenally determined truth conditions in a "web of belief") (p. 526). The claim that phenomenology fixes non-perceptual propositional attitudes remains unjustified, for the reasons considered above: a particular phenomenology may be associated with any of several different beliefs, and a particular belief may be associated with any of several phenomenologies. There is nothing about a particular phenomenology, say an image, that makes it of a particular belief.

To avoid confusion, HT's view should be distinguished from a distinct, defensible, and much weaker view. We make the distinction, but do not consider the plausibility of the other view. If the intentionality of phenomenology is correct, 
there may be perceptual beliefs with phenomenal intentional content, and likewise there may be what we will call phenomenological beliefs, that is, beliefs about the phenomenology associated with particular propositional attitudes. This would, if true, be sufficient for the truth of the claim that phenomenal duplicates share some constitutively determined intentional content. However, this does not support claims that non-phenomenological non-perceptual beliefs of the kind that HT discuss are constitutively determined by phenomenology.

\subsection{Non-sensory phenomenology}

Graham et al. (2007) want to construe phenomenology loosely as the unique whatit-is-likeness of entertaining a proposition; for example:

the what-it-is-like of undergoing an occurrent psychological state with the content that Clinton would have been a more successful candidate than Kerry (p. 473).

The idea here is that each psychological state is associated with a unique feeling that, in accordance with phenomenal intentionality, determines the content (or part of the content) of that state. Further, this phenomenology is not sensory; it does not consist merely of mental images or subvocalizations. It is some other type of phenomenal state.

The existence of other non-sensory phenomenal states is not implausible, though it is unclear exactly what they are. It might be useful to consider them as akin to a mood or emotion (assuming that the correct account of these is not a reduction to a combination of sensory phenomenology).

Given the existence of non-sensory phenomenology there are two options for how GHT's phenomenal intentionality for propositional attitude states can be understood.

\subsubsection{Simples}

The first option is that phenomenal states of the relevant kind are simples that correspond one to one with propositional attitude states. This seems psychologically implausible since there are infinitely many propositional attitude states and only a finite number of simple, non-perceptual (and non-sensory), phenomenal states.

Intentional propositional attitude states are likely compositional. The atomic meaningful parts, plus a syntax for combining them, determines the meanings of the complex states. Consequently, propositional attitude states are productive in the sense that the possible combinations of their parts are unbounded. On the other hand, if the associated phenomenal states are simples, there is no obvious method for a finite mind to generate infinitely many of them. Things are perhaps different with perception as the environment provides continual novel stimulation. (Sensory states also may be compositional, but that is the topic of the next section.) In order for there to be enough non-perceptual states for one-to-one correspondence something like phenomenal compositionality is required. 


\subsubsection{Composition}

The second possibility is that non-sensory phenomenal states compose, and thus that they can achieve a one-to-one correspondence with propositional attitude states through this composition. To explore this possibility it is useful to return briefly to the discussion of sensory phenomenal states.

Sensory phenomenal states don't seem to compose in a way that is intuitively useful. HT make several claims of the following sort: "sensory-phenomenal experience, by itself, determines conditions of accuracy" (p. 524); "occurrent states in the phenomenal duplicate, by virtue of having the same phenomenologically determined truth conditions as yours, are thereby subject to the same methods of accuracy assessment" (p. 525). These claims would be more plausible if there was a structural isomorphism between phenomenology and propositions: that is, if the components of propositions which determine the proposition's truth conditions were reflected by components of phenomenology which combine to determine truth conditions. An exact isomorphism is perhaps not strictly necessary, but at a minimum there must be some phenomenal difference to capture the different (narrow) truth conditions of all possible propositions. Furthermore, as we saw above, if the phenomenal differences do not correspond in some intuitive way to the propositional differences that produce different truth conditions, HT's proposal will lose much of its appeal: there will be little reason to think that phenomenology determines truth conditions.

Since sensory phenomenology doesn't seem to have the right kind of separable parts, and since its parts are certainly not compositional like those of a proposition, it is not possible for it to be structurally isomorphic with a proposition. Consider HT's example, from Quine, of an occurrent thought that rabbits have tails (p. 522). HT claim that "it seems plainly false-and false for phenomenological reasonsthat there is indeterminacy as to whether one is having a thought that rabbits have tails or whether one is instead having a thought that (say) collections of undetached rabbit parts have tail subsets" (p. 522). So HT take the view that, because there is a difference in the truth conditions of "Rabbits have tails" (R1) and "Undetached rabbit parts have tail subsets" (R2), that difference must be reflected in-because determined by-differences in the respective phenomenologies of those occurrent beliefs.

Propositions like R2 are constituted by several parts-referring terms, such as tails, and relations, such as being a subset of - and the truth conditions of the whole are fixed once these compositional entities and their extensions are fixed. But the phenomenology associated with R2 is not plausibly compositional in this way: there is no part of the phenomenology that is the 'subset part' and that combines with the 'rabbit part' to determine conditions of accuracy. Consider that the phenomenology (an image for example) one might have when believing that "Rabbits hop small fences," is not a combination of the rabbit image, with the small fence image, and the 'hopping over' relation; for one thing, the rabbit would now be hopping and there is no reason to think that the component rabbit image would be of a hopping rabbit (and the component rabbit image would of course be different in other phenomenologies concerning sleeping rabbits, or cooking rabbits). 
This is a problem for HT even if we grant that thoughts about tail subsets have a different phenomenology than thoughts about tails. (The contrast between rabbits and undetached rabbit part thoughts is less convincing, but we can grant this too.) So, for example, suppose that tail subset thoughts involve, in addition to tail images, subset images. (Of course, as HT claim, phenomenology consists of more than images, and we will return to non-sensory phenomenology shortly.) Yet, the necessary compositional structure is still lacking. Consider two sentences expressing propositions:

(S1) There are subsets and there are rabbit tails and there are undetached rabbit parts.

(R2) Undetached rabbit parts have tail subsets.

There is no reason to think that thoughts about the propositions expressed by these two sentences could not have the same phenomenology, even granting subset and undetached phenomenology. Yet, they have different truth conditions. Thus, phenomenal duplicates may be in an intentional state corresponding to either of these sentences. Thus, phenomenology fails to determine or fix intentionality. ${ }^{10}$

Hence, two points: first, the component elements of sensory phenomenology don't separate and recombine, so it is not easy to see how sensory phenomenology is going to map onto narrow truth conditions. Second, sensory phenomenology doesn't have the structure to express the difference between thoughts like S1 and R2. In order to avoid these objections HT would have to show that phenomenology has a compositional structure relevantly isomorphic with that of propositions, or find some other less obvious way of mapping the phenomenal onto the phenomenal intentional.

It may seem that the non-sensory can be helpful here. However, it is even less clear how non-sensory states compose. Non-sensory phenomenology may be able to account for differences between thoughts like S1 and R2, but it is even less clear what it would mean to say that such states have parts that compose, and so does not seem that there are enough non-sensory states to correspond to the possible propositional attitude states.

We might imagine that there are non-sensory what-it's-like states that correspond to each of the components of a proposition. However, in this case it is even more apparent than in the sensory case that these fleeting phenomenal impressions do not themselves have the properties that allow them to enter into complex states with the same truth conditions (what are the non-sensory phenomenal parts of the what-it'slike of the having of an occurrent state with the content that Clinton would have been a more successful candidate than Kerry?). If there are such feelings it is clear that they cannot be easily decomposed on their own terms.

This can also be made apparent by assuming only a one-way implication between the phenomenal and the intentional here. With a one-way implication the intentional

\footnotetext{
${ }^{10}$ Ironically, if HT agreed with Quine that R1, R2 and S3 were indeterminate thoughts, then it would be unproblematic if they shared a phenomenology - that phenomenology could determine the shared indeterminate content. However, since tail subsets have a different phenomenology than tails, they should determine a different content.
} 
does not inform us about the phenomenal. Without the necessary supervenience relations we cannot draw conclusions about the phenomenal.

If we assume covariation between the non-sensory phenomenal states and the propositional attitude states, the required compositional structure is again apparent. It is intuitively present and in this case the intentional does inform us about the phenomenal; that is, if the intentional is fixed so is the phenomenal. Since the intentional states are compositional, and on this view the phenomenal states track the intentional, the phenomenal states may be compositional and thus may be sufficient in number to match the intentional states in a psychologically plausible way.

The problem with this option is, as in the case of perceptual phenomenal intentional content, there is no longer any ground for the priority claim. Worse, in this case there is reason to believe that the intentional is prior: the intentional clearly has and intuitively provides the compositional structure to the phenomenal.

Thus, we can conclude that the phenomenal does not determine the content of propositional attitudes; that is, phenomenal intentionality for propositional attitude states is false. To review, there are two possible types of phenomenology that are candidate determiners of propositional attitude states: sensory and non-sensory. It is implausible that the sensory phenomenal states determine propositional attitude states since they vary independently (identical meatloaf images may be associated with different contents and one meatloaf thought maybe associated with two distinct images, for example). Further, sensory phenomenology doesn't compose, or at least not in a way that is similar to the relevant intentional states. Thus, non-perceptual sensory phenomenal states would not be psychologically capable of playing the necessary role.

Non-sensory phenomenal states can either be simples that determine the propositional attitude states or they can be states that compose. It is psychologically implausible that there are enough simple non-perceptual phenomenal states to correspond to the propositional attitude states. If the non-sensory phenomenal states compose, it can only be due to their standing in an equivalence relation to, that is covarying with, intentional states. In this case the compositionality is from the intentional states. Thus, there can only be enough non-sensory states to play the role of determining the intentional states if equivalence is embraced, but in that case the phenomenal does not seem prior.

The phenomenal intentionality thesis fails for both perceptual contents and propositional attitude states. The conjunction of the claims IP and Phenomenal Intentionality is false; the intentionality of phenomenology can only be made plausible with acceptance of the equivalence relation between the relevant phenomenal and intentional states, but this undermines the phenomenal intentionality claim. Both conjuncts cannot be true simultaneously.

The conjunction of PI and Phenomenal Intentionality is also false. PI is only plausible given compositionality, which requires the acceptance of equivalence for the relevant phenomenal and intentional states, but this provides a reason to believe that the intentional determines the phenomenal rather than the phenomenal the intentional. 
In conclusion, against Horgan and Tienson's claim that phenomenology is sufficient to determine a broad and important class of narrow content, we have argued that:

(a) there is inadequate reason to think phenomenology determines perceptual belief;

(b) there is reason to doubt that phenomenology determines any species of non-perceptual (and non-phenomenological) intentionality;

(c) worries can be raised about the capacity of phenomenology to map onto intentionality in a way that would be appropriate for any determiner of content/fixer of truth conditions.

Acknowledgments This paper benefited from discussions with David Bourget and Ben Blumson regarding early drafts. Audience members at the Australian National University also provided valuable feedback on an earlier version of the paper.

\section{References}

Addis, L. C. (1989). Natural signs: A theory of intentionality. Philadelphia, PA: Temple University Press. Bach-y-Rita, P. (1972). Brain mechanisms in sensory substitution. New York: Academic Press.

Chalmers, D. (2004). The representational character of experience. In B. Leiter (Ed.), The future for philosophy (pp. 153-181). New York: Oxford University Press.

Graham, G., \& Horgan, T. (2000). Mary, Mary, quite contrary. Philosophical Studies, 99, 59-87.

Graham, G., \& Horgan, T. (2008). Qualia realism: Phenomenal contents and discontents. In E. Wright (Ed.), The case for qualia (pp. 89-107). Cambridge, MA: MIT Press.

Graham, G., Horgan, T., \& Tienson, J. (2007). Consciousness and intentionality. In M. Velmans \& S. Schneider (Eds.), The Blackwell companion to consciousness (pp. 468-484). Oxford: Blackwell.

Graham, G., Horgan, T., \& Tienson, J. (2009). Phenomenology, intentionality and the unity of mind. In A. Beckerman \& B. McLaughlin (Eds.), The Oxford handbook of the philosophy of mind (pp. 512-535). New York: Oxford University Press.

Horgan, T., \& Tienson, J. (2002). The intentionality of phenomenology and the phenomenology of intentionality. In D. J. Chalmers (Ed.), Philosophy of mind: Classical and contemporary readings (pp. 520-532). New York: Oxford University Press.

Horgan, T., Tienson, J., \& Graham, G. (2005). Phenomenal intentionality and the brain in a vat. In R. Schantz (Ed.), The externalist challenge: New studies in cognition and intentionality (pp. 297-317). Berlin: De Gruyter.

Horgan, T., Tienson, J., \& Graham, G. (2006). Internal-world skepticism and the self-presentational nature of phenomenology. In U. Kriegel \& K. Williford (Eds.), Consciousness and selfrepresentation (pp. 41-61). Cambridge, MA: MIT Press.

Kriegel, U. (2009). Subjective consciousness: A self-representational theory. New York: Oxford University Press.

Loar, B. (2002). Transparent experience and the availability of qualia. In Q. Smith \& A. Jokic (Eds.), Consciousness: New essays (pp. 77-96). New York: Oxford University Press.

Loar, B. (2003). Phenomenal intentionality as the basis of mental content. In M. Hahn \& B. Ramberg (Eds.), Reflections and replies: Essays on the philosophy of Tyler Burge (pp. 229-258). Cambridge, MA: MIT Press.

McGinn, C. (1988). Consciousness and content. Proceedings of the British Academy, 74, 219-239.

Pitt, D. (2004). The phenomenology of cognition or 'what is it like to think that P?'. Philosophy and Phenomenological Research, 69(1), 1-36.

Searle, J. (1992). The rediscovery of the mind. Cambridge, MA: MIT Press.

Siewert, C. (1998). The significance of consciousness. Princeton, NJ: Princeton University Press.

Siewert, C. (2003). Consciousness and intentionality. In E. Zalta (Ed.), Stanford encyclopedia of consciousness. Oxford: Blackwell.

Strawson, G. (1994). Mental reality. Cambridge, MA: MIT Press. 
Williford, K. (2005). The intentionality of consciousness and consciousness of intentionality. In G. Forrai \& G. Kampis (Eds.), Intentionality: Past and future (pp. 143-156). Amsterdam: Rodopi.

Wilson, R. A. (2003). Intentionality and phenomenology. Pacific Philosophical Quarterly, 84, 413-431. 